\title{
No sequence variation in part of the hexon and the fibre genes of adenovirus 8 isolated from patients with conjunctivitis or epidemic keratoconjunctivitis (EKC) in Norway during 1989 to 1996
}

\author{
K Vainio, E Borch, A L Bruu
}

\begin{abstract}
BackgroundlAims-Several local epidemics of keratoconjunctivitis/conjunctivitis caused by adenovirus type 8 (Ad8) occurred in Norway from August 1995 to May 1996. A smaller epidemic occurred in 1992. The Ad8 hexon forms the surface of the virion and contains the hypervariable regions loop $I_{1}$ and loop $I_{2}$. The fibre mediates the primary contact with cells. Sequence variation in hexon and fibre genes might play an important role in the pathogenicity of adenoviruses. The aim of this study was to investigate the genetic variability at the hexon and fibre genes in 26 strains of Ad8 isolated from 1989 to 1996.

Methods-The genetic variability of 26 strains of Ad8 isolated from 1989 to 1996 was studied by sequencing part of the hexon and fibre genes. The Ad8 sequences were compared with each other and with two Ad8 strains from the EMBL database. In addition, 14 of the 26 isolates were subjected to restriction endonuclease analysis.

Results-No significant sequence variation was seen during the six year period. Conclusion-The Ad8 strains causing epidemics of keratoconjunctivitis/ conjunctivitis in Norway are genetically stable.

(f Clin Pathol 2001;54:558-561)
\end{abstract}

Keywords: adenovirus 8; molecular epidemiology; conjunctivitis

Adenoviruses (Ad) comprise 49 serotypes that are classified into six subgenera $(\mathrm{A}-\mathrm{F})$. They are DNA viruses that infect a variety of tissues and are responsible for a wide range of clinical conditions. Conjunctivitis may be caused by a broad array of adenoviruses, whereas epidemic keratoconjunctivitis (EKC) has been associated with serotypes $8,19 \mathrm{a}$, and 37 (subgenus D). EKC is a severe, painful, and highly contagious eye infection, which often causes outbreaks in settings where people seek ophthalmological care. The infection is frequently transmitted by the ophthalmologist's hands, contaminated instruments, or eye drops. EKC can last for as long as four weeks and is predominantly caused by Ad8.

Further taxonomic subdivision at the genome level can be achieved by restriction endonuclease (RE) analysis, which has become an important tool in adenovirus epidemiology. Detailed RE maps, as well as nucleotide sequences of hexon and fibre genes, have been published for Ad8. However, only a few other studies have used DNA sequencing to demonstrate genetic variation in Ad8 during an epidemic. To date, only limited data are available on the molecular epidemiology of Ad8.

The hexons constitute a large proportion of the surface of the virion and determine, together with the fibre polypeptides, the serotype specificity of the virus. The hypervariable regions of the Ad8 hexon are located on loops $I_{1}$ and $I_{2}$, and form the surface of the virion. The fibre is responsible for attachment of the virus to its receptor on the cellular membrane and therefore mediates the primary contact with the cell. Antigenic variation is important with respect to the molecular epidemiology of the virus. Sequence variation in hexon and fibre genes may play an important role in the pathogenicity of adenoviruses causing conjunctivitis and EKC.

Several outbreaks of acute EKC/ conjunctivitis occurred in different parts of Norway during the period of August 1995 to May 1996. Local outbreaks were observed in Oslo, and in the counties of Vestfold and South Trøndelag. In the county of North Trøndelag there was a large epidemic. In 1992, a small summer epidemic of acute EKC was observed in the city of Fredrikstad (eastern Norway), in addition to several sporadic cases occurring during June and October in other parts of the country. The aim of our study was to analyse the genetic variability of $\mathrm{Ad} 8$ isolated from patients with conjunctivitis/EKC during an epidemic and over a longer period of time. Genetic variation was studied by sequencing part of the hexon and the fibre genes. In addition, some of the isolates were subjected to RE analysis. $^{1-8}$

\section{Material and methods}

CLINICAL SAMPLES AND VIRUS ISOLATION

Twenty six clinical isolates of Ad8 obtained from different regions of Norway were used to study the genetic variation of part of the fibre and hexon genes. Both outbreaks and sporadic cases were included in the investigation. Seven of the Ad8 positive isolates analysed were from 1992, 14 were from different outbreaks in 
Table 1 Primers used for amplification and sequencing of adenovirus 8

\begin{tabular}{|c|c|c|c|c|}
\hline Primer & Location & Sequence $\left(5^{\prime} \rightarrow 3^{\prime}\right)$ & Amplimer & Length $(b p)$ \\
\hline F1 forward & Fibre gene & AAGGGATGTCAAATTCC & & \\
\hline F199 reverse & Fibre gene & AAGATTTGAAGATTCCA & $\mathrm{F} 1 / \mathrm{F} 199$ & $828 \mathrm{bp}$ \\
\hline H1.1 forward & Hexon gene & TTTGACATCCGCGGCGT & & \\
\hline $\mathrm{H} 3$ forward & Hexon gene & TTGCAAGACAGAAACAC & $\mathrm{H} 3 / \mathrm{H} 8$ & $250 \mathrm{bp}$ \\
\hline H8 reverse & Hexon gene & TATCATTTTGACCTTGAGC & $\mathrm{H} 1 / \mathrm{H} 8$ & $1069 \mathrm{bp}$ \\
\hline
\end{tabular}

For F1 and F199 primers see Pring-Åkerblom and Adrian. ${ }^{2}$

For $\mathrm{H} 1.1$ and $\mathrm{H} 3$ primers see Eiz et al. ${ }^{11}$

For the H8 primer see Pring-Åkerblom and Adrian. ${ }^{7}$

$1995 / 1996$, and five were from the nonepidemic years during 1989 to 1994: 1989 (one), 1991 (two), 1993 (one), and 1994 (one). In addition, 14 of the isolates collected during the 1992 and 1995/96 epidemics were subjected to RE analysis. The viruses were isolated from conjunctival swabs by conventional cell culture methods. The Ad8 isolates characterised in our study were associated with conjunctivitis or EKC, and the viral serotypes were determined using serum pools from the Swedish Institute for Infectious Disease Control, Stockholm, Sweden (SMI). The isolates were retrospectively propagated in HeLa, A 549, and human embryonic lung diploid fibroblast cells for viral DNA extraction. When an extensive cytopathic effect was observed, the virus infected cells were harvested by freezing and thawing. Detailed clinical and epidemiological data were not made available to our laboratory.

DNA RESTRICTION ENZYME ANALYSIS

Viral DNA from 14 clinical isolates was extracted from infected cells by a modified method of $\mathrm{Hirt}^{9}$ and Jong et al. ${ }^{10}$ Samples containing $0.5 \mu \mathrm{g}$ of adenovirus DNA were digested with the following enzymes: Hind III, Bgl II, Bst EII, Bam HI, and Sma I. Incubations were performed according to the manufacturers' instructions. Fragments were separated by electrophoresis in $0.8 \%$ agarose gels stained with ethidium bromide. The DNA restriction patterns were compared with each other and to the prototype Ad8 (Trim, ATCC).

PCR, CYCLE SEQUENCING, AND SEQUENCE

ANALYSIS

Twenty six clinical isolates were used to study the nucleotide sequence variation in part of the

Table 2 Adenoviruses (Ad) serotyped at the department of virology, National Institute of Public Health during 1989 to 1996

\begin{tabular}{|c|c|c|c|c|c|c|c|c|c|c|}
\hline Subfamily & Serotype & 1989 & 1990 & 1991 & 1992 & 1993 & 1994 & 1995 & 1996 & Total \\
\hline & Adeno & 3 & 2 & 1 & 8 & 1 & 12 & 6 & 18 & 51 \\
\hline C & Ad1 & 8 & 4 & 2 & 21 & 8 & 11 & 14 & 8 & 76 \\
\hline C & Ad2 & 15 & 9 & 10 & 25 & 25 & 21 & 12 & 11 & 128 \\
\hline B & Ad3 & 34 & 29 & 5 & 9 & 2 & 18 & 26 & 1 & 122 \\
\hline $\mathrm{E}$ & $\mathrm{Ad} 4$ & & & & 7 & 2 & 2 & & 1 & 12 \\
\hline C & Ad5 & 4 & 1 & & 8 & 14 & 14 & 6 & 3 & 50 \\
\hline C & Ad6 & & & & 1 & 4 & & 1 & 1 & 7 \\
\hline B & $\mathrm{Ad} 7$ & & & 4 & & & 7 & 8 & 5 & 26 \\
\hline D & Ad8 & 1 & & 3 & 16 & 2 & 3 & 13 & 39 & 77 \\
\hline D & Ad10 & & 1 & & & 2 & & & & 3 \\
\hline A & Ad12 & & & & & & 1 & & & 1 \\
\hline D & Ad13 & & & & & & & & 1 & 1 \\
\hline B & Ad 14 & & 4 & & & & & & & 4 \\
\hline D & Ad15 & & & & & & & & 1 & 1 \\
\hline B & Ad16 & & & & & & & & 1 & 1 \\
\hline A & Ad18 & & & & 2 & & 4 & & & 6 \\
\hline D & Ad19 & & & & 4 & & & 1 & 4 & 9 \\
\hline D & $\operatorname{Ad} 29$ & 2 & & & & 2 & & & & 4 \\
\hline D & Ad30 & & & & & & & & 1 & 1 \\
\hline B & Ad35 & & & & & 5 & & & & 5 \\
\hline
\end{tabular}

fibre gene (table 1; primers F1/F199). In addition, a fragment covering loop $\mathrm{I}_{2}$ of the hexon gene was sequenced from 14 clinical isolates (table 1; primers $\mathrm{H} 3 / \mathrm{H} 8$ ). Viral DNA was extracted from $200 \mu \mathrm{l}$ of cell lysate with the QIAamp blood kit (Qiagen, Düsseldorf, Germany) according to the manufacturer's instructions. Polymerase chain reaction (PCR) amplification was performed using a GeneAmp 9600 (PE Applied Biosystems, Perkin-Elmer, Foster City California USA) and reaction conditions were as follows: $10 \mathrm{mM}$ Tris/ $\mathrm{HCl}$ ( $\mathrm{pH} 8.3$ ), $50 \mathrm{mM} \mathrm{KCl}, 1.5 \mathrm{mM} \mathrm{MgCl}_{2}, 200 \mu \mathrm{M}$ of each dNTP, 40 pmol of each primer, and $1 \mathrm{U}$ Taq DNA polymerase (Perkin-Elmer). Briefly, $25 \mu \mathrm{l}$ of purified viral DNA was added to $75 \mu \mathrm{l}$ PCR mixture and amplification was performed under the following conditions: initial denaturation at $95^{\circ} \mathrm{C}$ for four minutes, followed by 40 cycles at $94^{\circ} \mathrm{C}$ for 30 seconds, annealing at $45^{\circ} \mathrm{C}$ for 30 seconds, elongation at $72^{\circ} \mathrm{C}$ for 60 seconds, and a final elongation at $72^{\circ} \mathrm{C}$ for five minutes. Table 1 shows the primer sequences and positions. The amplification products were analysed by electrophoresis in 2\% agarose gel containing ethidium bromide.

Second round PCR products were sequenced directly in both directions with the second round PCR primers using an ABI PRISM 310 genetic analyser and an ABI PRISM dye terminator cycle sequencing kit (Perkin-Elmer). Sequences were edited using the Sequencer 3.0.1. program (Gene Code, Ann Arbor, Michigan, USA). The sequence alignment and a dendrogram were generated using the CLUSTAL $\mathrm{X}$ program version 1.64b. The trees were drawn using TreeView (WIN32) version $1.64 \mathrm{~b} .{ }^{12}$ The EMBL database accession numbers for the two Ad8 strains are X74660 and S75136.

\section{Results and discussion}

The department of virology, National Institute of Public Health is a reference laboratory for adenoviruses in Norway. Approximately 90\% of all adenoviruses isolated from patients in Norway are submitted to our laboratory for serotyping, thus enabling us to study the epidemiology of these viruses. Table 2 shows the total number of adenoviruses serotyped during 1989 to 1996 in our laboratory. As seen in table 2, Ad8 was among the dominant serotypes only during the epidemic years 1992 and 1995-6. All the Ad8 positive isolates submitted to our laboratory were associated with conjunctivitis or EKC.

In total, 26 strains of Ad8 isolated during 1989 to 1996 were selected for our study. Four of the 14 samples collected during the epidemic period during 1995 to 1996 belonged to the large epidemic occurring in North Trøndelag. This epidemic was unusually large, with more than 100 people infected. Seven of the 14 samples came from three smaller outbreaks occurring in the Oslo region, and in the cities of Tønsberg and Trondheim. The remaining three samples were from sporadic cases occurring in different places within the Oslo region. Five of the seven samples collected during 1992 belonged to one epidemic occurring in 


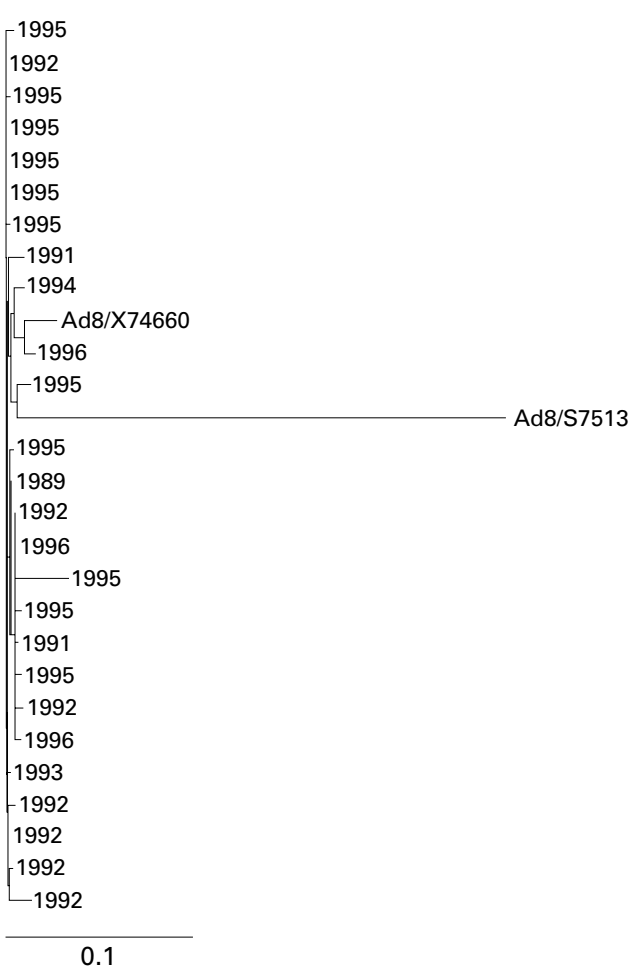

Figure 1 Phylogenetic analysis based on nucleotide sequences covering part of the fibre gene from adenovirus (Ad8) isolates (between F1/F199 primers). Sequences included are the 26 Ad8 isolates collected during 1989 to 1996 and two Ad8 strains from the EMBL database. The sequences were edited using the Sequencer program and aligned using CLUSTAL X. The tree was drawn using TreeView (WIN32). The EMBL accession numbers for the two Ad8 strains are X74660 and $S 7513$.

Fredrikstad during June. The remaining two samples were from sporadic cases, one from Oslo and one from northern Norway. Most of the Ad8 positive cases analysed were infected through secondary contacts such as family members, friends, or neighbours.

In total, 26 clinical isolates were DNA sequenced. No significant sequence variation was observed between the clinical isolates during the six year period. Fourteen of the 26 isolates were also subjected to RE analysis. All the $\mathrm{RE}$ analyses gave identical profiles with the 14 isolates and the Ad8 prototype. Figure 1 shows the genetic relation between the clinical isolates. As shown in the dendrogram, the isolates could not be grouped into distinct clusters. The Ad8 isolates, with accession number X74660, were closely related to the Norwegian isolates. The sequence identity over 780 nucleotides was between $96.5 \%$ and $99.4 \%$ when X74660 was compared with our isolates. The dendrogram based on the hexon gene (not shown) and the RE maps (not shown) yielded similar results. In this part of the genome only a few nucleotide substitutions have accumulated during 1989 to 1996. Therefore, our results suggest that Ad8 is well conserved, both over a wide geographical area and over time, in this part of the genome. It is also unlikely that coinfection with other Ad8 variants has occurred. The Ad8 genome has been reported to be fairly stable because only a limited number of different Ad8 variants have been found. ${ }^{13-17}$ Jong et al only found different Ad8 variants among isolates obtained from different epidemics. ${ }^{10}$ All these studies have been based on RE analysis. Our data, which are based primarily on nucleotide sequencing, show no sequence variation between Ad8 isolated during the epidemic and the nonepidemic years. If the pathogenicity of the Ad8 viruses has changed over time, it is not associated with sequence variation in the sequenced regions of the fibre and hexon genes.

Based on our knowledge of clinical and epidemiological data, some of the Ad8 positive cases were probably exposed directly to contaminated instruments in an institution/clinic. However, most of the cases have evidently been infected through family members, friends, or neighbours. These data indicate that infections with Ad8 are easily spread in a susceptible population. This may partly explain our results indicating that the same Ad8 variant is circulating in a given population during an epidemic. The 1995-6 epidemic was probably caused by insufficient hand hygiene among the Ad8 positive individuals. In addition, a large outbreak of EKC was seen in an eye department during the 1995-6 epidemic. The investigation showed that the index case was hospitalised as a corridor patient. Secondary cases were observed after a couple of days, both among other patients and hospital personal. Poor hand hygiene was thought to be the main cause of this outbreak. Therefore, information concerning good hand hygiene is important to prevent the spread of eye infections caused by Ad8, and in institutions it is important to isolate infected patients.

Several adenovirus serotypes (types 3, 4, 8, 19, and 37) are linked to acute conjunctivitis. The standard virus isolation method for detecting adenovirus is time consuming, and many groups have therefore developed PCR as a tool for detecting adenovirus from conjunctival samples. A good correlation between serotyping with nested PCR and cell culture has been demonstrated. Nested PCR has proved to be both more rapid and sensitive than the standard viral culture method. Therefore, PCR has considerable potential for the rapid diagnosis of viral eye infections. In addition, simultaneous detection of several viruses associated with eye infections can be achieved using a multiplex PCR design. PCR products can also be analysed further by DNA sequencing to improve serotyping or to study the molecular epidemiology of adenoviruses.

In conclusion, our results indicate that $\mathrm{Ad} 8$ causing conjunctivitis circulates as a single variant in Norway. For a better understanding of the molecular epidemiology of Ad8, further studies are needed to compare nucleotide sequence variation in different parts of the genome, and to study a larger number of isolates over a longer period of time.

\footnotetext{
1 Pring-Åkerblom P, Heim A, Trijssenaar J. Conserved sequences in the fibers of epidemic keratoconjunctivitis
associated human adenovirus. Arch Virol 1997;142:205-11. 2 Pring-Åkerblom P, Adrian T. Characterization of adenovi2 Pring-Akerblom P, Adrian T. Characterization of adeno
rus subgenus D fiber genes. Virology 1995;206:564-71.
} 
3 Jernigan JA, Lowry BS, Hayden FG, et al. Adenovirus type 8 epidemic keratoconjunctivitis in an eye clinic: risk factors

4 Johansson ME, Ahrel-Andersson MA, Gudnadottir S Molecular epidemiology of adenoviruses isolated in Iceland during 1988-1990. F Virol Methods 1993;42:193-206.

5 Arnberg N, Mei YF, Wadell G. Fiber genes of adenoviruses with tropism for the eye and the genital tract. Virology 1997;227:239-64.

6 Pring-Åkerblom P, Trijssenaar J, Adrian T. Sequence characterization and comparison of human adenovirus subgenus B and E hexons. Virology 1995;212:232-6.

7 Pring-Åkerblom P, Adrian T. Type- and group-specific polymerase chain reaction for adenovirus detection. Res Virol 1994;145:25-35.

8 Johansson ME, Andersson MA, Thörner PÅ. Adenoviruses isolated in the Stockholm area during 1987-1992: restriction endonuclease analysis and molecular epidemiology. Arch Virol 1994;137:101-15.

9. Hirt B. Selective extraction of polyoma DNA from infected mouse cell cultures. F Mol Biol 1967;26:365-9.

10 Jong J, Démazure M, Legrand-Quillien MC, et al. New developments in the molecular epidemiology of adenovirus 8 keratoconjunctivitis. $\mathcal{F}$ Med Virol 1992;38:102-7.
11 Eiz B, Adrian T, Pring-Åkerblom P. Immunological adenovirus variant strains of subgenus D: comparison of the hexon and fiber sequences. Virology 1995;213:313-20.

12 Page RD. TREEVIEW: an application to display phylogenetic trees on personal computers. Comput Appl Biosci 1996;12:357-8.

13 Mahafzah A, Landry M. Restriction endonuclease analysis of adenovirus isolates from sporadic and epidemic ocular infections: experience in a clinical laboratory. $7 \mathrm{Med}$ Microbiol 1994;40:385-8.

14 Fujii SI, Nakozono M, Sawada J, et al. Restriction endonuclease cleavage analysis of adenovirus type 8: two new subtypes from patients with epidemic keratoconjunctivitis in Sapporo, Japan. Fpn f Med Sci Biol 1983;36:307-13.

15 Corsaro D, Gut JP, Faou AL. Molecular epidemiology of ocular isolates of adenovirus 8 obtained over nine years. $\mathcal{F}$ Clin Pathol 1999;52:860-1.

$16 \mathrm{Kemp}$ MC, Hierholzer JC. Three adenovirus type 8 genome types defined by restriction enzyme analysis: prototype statypes defined by restriction enzyme analysis: prototype sta-
bility in geographically separated populations. 7 Clin Microbility in geographical $1986 ; 23: 469-74$.

17 Adrian T, Wolf U, Lauer HJ, et al. Restriction site mapping of adenovirus type 8 genome types. Res Virol 1990;141: $611-12$.

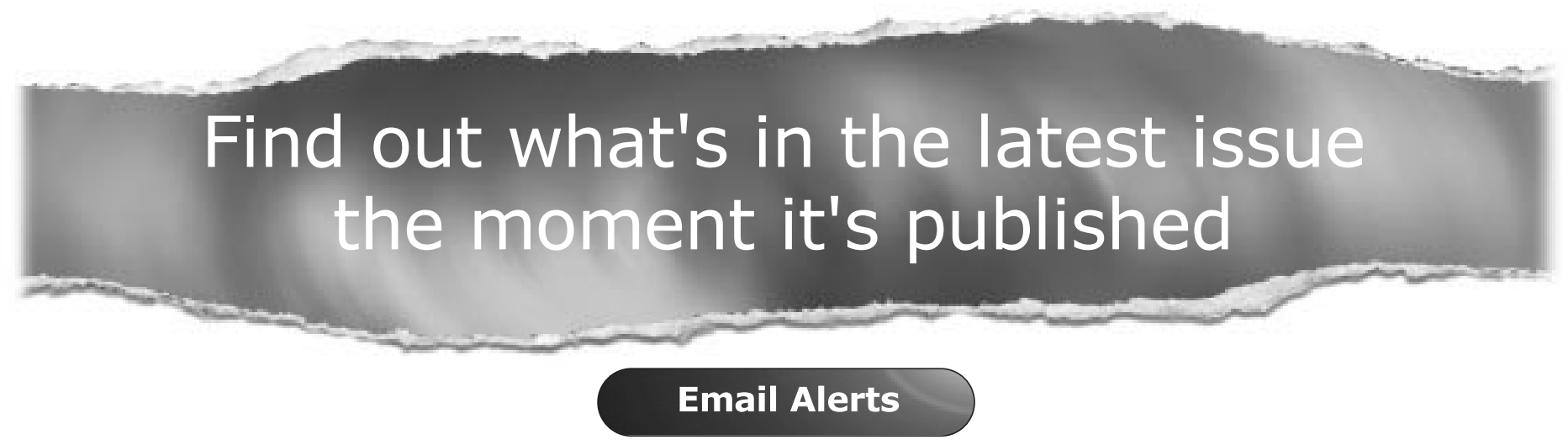

Sign up to receive the table of contents by email every month. You can select from three alerts:

Table of Contents (full), TOC Awareness (notice only); Journal of Clinical Pathology related announcements.

\section{www.jclinpath.com}

